American Journal of Pharmaceutical Education 2018; 82 (7) Article 7000.

\title{
COMMENTARY
}

\section{Commit Yourself to Improvement of Student Learning}

\author{
Margarita V. DiVall, PharmD, MEd, ${ }^{a}$ Lauren Schlesselman, PharmD, MA EdPsych ${ }^{\text {b,c }}$ \\ ${ }^{a}$ Northeastern University School of Pharmacy, Bouvé College of Health Sciences, Boston, Massachusetts \\ ${ }^{\mathrm{b}}$ Center for Excellence in Teaching and Learning, University of Connecticut, Storrs, Connecticut \\ ${ }^{c}$ Associate Editor, American Journal of Pharmaceutical Education, Arlington, Virginia \\ Submitted February 5, 2018; accepted February 17, 2018; published September 2018.
}

Keywords: assessment, faculty development, student learning

The word "assessment" may be the most dreaded word in higher education. Many faculty members associate assessment with institutional compliance and accreditation, which come with self-studies, site visits, and evaluative judgments. While assessment can take on many forms, it should always be about quality assurance and focused on improving programs and student learning. Having conversations that avoid assessment jargon (often only understood by assessment experts) can reduce the deep chasm that often exists between assessment administrators and faculty members.

Instead faculty members are encouraged to think about assessment more as educational effectiveness with the goal of improvement. ${ }^{1}$ Ask yourself "what am I doing to find out whether students learned this material? How do I know that I have actually made an impact on student learning? What was that impact?" More often than not, you are doing a lot and the next question might be: "Once I have the information about student learning, how am I using it to further improve teaching and learning in my classroom or at the experiential site?" This is what we assessment people call - closing the assessment loop and is, unfortunately, often the step that is skipped the most. ${ }^{2}$

Just giving an examination does not ensure the students learned or that you are actually measuring achievement of the learning objectives. Further, many of the skills and attitudes so important for pharmacy students are difficult to measure via a test, including critical thinking and skills and attitudes in the affective domain. When analyzing performance, it is important to not only focus on grade distribution, but also on psychometrics that indicate whether the assessment can be considered reliable and valid through an examination of individual item performance and alignment of individual items to the learning objectives. Local assessment

Corresponding Author: Margarita V. DiVall, Northeastern University School of Pharmacy, Bouvé College of Health Sciences, 140 The Fenway, R218TF, Boston, MA 02115. Tel: 617-373-5370. E-mail: m.divall@northeastern.edu expertise can be leveraged when faculty members are uncertain on how to interpret item analyses reports or develop question items aligned to learning objectives.

Faculty members are encouraged to employ a variety of formative and summative assessment strategies to ensure they go beyond measuring lower level Bloom's knowledge using multiple choice tests. ${ }^{3}$ Although the idea of more classroom assessments may make some faculty members cringe because of the time needed to grade, it is important to remember that not all tools need to be graded. Formative tools provide opportunities to understand what your students comprehend, modify your teaching, and even provide feedback without grading.

Regardless of the tools used, planning and mapping to learning outcomes is critical. ${ }^{4}$ Many faculty members will say they cannot write their examination questions until they have actually taught the class. When learning objectives are well designed in advance of the course, faculty members can and should develop evidence of learning tools prior to teaching. Because your learning objectives state what a student will know or be able to do, your evidence of learning should be designed for students to demonstrate those skills and knowledge, rather than the individual recall of facts.

Once the evaluation of the examination has been completed and scoring finalized, it is important to examine performance at the level of individual learning outcomes. Many schools use technology that allows faculty members to examine these data not only for each individual assessment but across their courses. Conversations about what constitutes acceptable performance at various stages of student education should take place among faculty colleagues. These benchmarks can be used to determine whether students are meeting these targets and what needs to be changed in the instruction to improve learning, especially in cases when students are underperforming. Finally, faculty members are encouraged to use the evidence of learning in their courses to document their teaching effectiveness as part of their teaching portfolios 


\section{American Journal of Pharmaceutical Education 2018; 82 (7) Article 7000.}

and promotion dossiers, as well as to generate scholarship of teaching and learning.

If these activities are done properly at the faculty and student level, the learning objectives, evidence of learning, reflection, and revision collectively contribute to assessment of learning and overall programmatic assessment plans. Focusing on quality and recognition of the faculty efforts to improve student learning can greatly contribute to establishing the sometimes elusive culture of assessment.

\section{REFERENCES}

1. Roscoe DD. Toward an improvement paradigm for academic quality. Lib Educ. 2017;103(1).

2. Banta TW, Blaich C. Closing the assessment loop. Change. 2011;43(1):22-27.

3. Angelo TA, Cross KP. Classroom Assessment Techniques: A Handbook for College Teachers. 2nd ed. San Francisco, CA: Jossey-Bass; 1993. 4. Wittstrom K, Cone C, Salazar K, Bond R, Dominguez K. Alignment of pharmacotherapy course assessments with course objectives. Am J Pharm Educ. 2010;74(5):Article 76. 